\title{
Kan Kültürlerinden İzole Edilen Mayaların Tanımlanmasında Ticari Bir Multipleks Tandem Polimeraz Zincir Reaksiyonu Yönteminin Değerlendirilmesi
}

\section{Evaluation of a Commercial Multiplex Tandem Polymerase Chain Reaction Method for the Identification of the Yeasts Isolated from Blood Cultures}

\author{
Halil ER ${ }^{1}(I D)$, Özlem KOYUNCU ÖZYURT²(ID), Betil ÖZHAK²(ID), Hatice YAZISIZ²(ID),

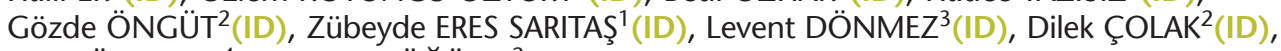 \\ Filiz GÜNSEREN ${ }^{4}(I D)$, Dilara ÖĞÜNÇ²(ID) \\ ${ }^{1}$ Sağlık Bilimleri Üniversitesi Antalya Eğitim ve Araştırma Hastanesi, Tıbbi Mikrobiyoloji Kliniği, Antalya. \\ ${ }^{1}$ Health Sciences University, Antalya Training and Research Hospital, Clinic of Medical Microbiology, Antalya, Turkey. \\ ${ }^{2}$ Akdeniz Üniversitesi Tıp Fakültesi, Tıbbi Mikrobiyoloji Anabilim Dalı, Antalya. \\ ${ }^{2}$ Akdeniz University Faculty of Medicine, Department of Medical Microbiology, Antalya, Turkey. \\ ${ }^{3}$ Akdeniz Üniversitesi Tıp Fakültesi, Halk Sağlı̆̆ Anabilim Dalı, Antalya. \\ ${ }^{3}$ Akdeniz University Faculty of Medicine, Department of Public Health, Antalya, Turkey. \\ ${ }^{4}$ Akdeniz Üniversitesi Tıp Fakültesi, Enfeksiyon Hastalıkları ve Klinik Mikrobiyoloji Anabilim Dalı, Antalya. \\ ${ }^{4}$ Akdeniz University Faculty of Medicine, Department of Infectious Diseases and Clinical Microbiology, Antalya, Turkey.
}

Makale Atıfı: Er H, Koyuncu Özyurt Ö, Özhak B, Yazısız H, Öngüt G, Eres Sarıtaş Z ve ark. Kan kültürlerinden izole edilen mayaların tanımlanmasında ticari bir multipleks tandem polimeraz zincir reaksiyonu yönteminin değerlendirilmesi. Mikrobiyol Bul 2020;54(4):596-605.

\section{ÖZ}

Kandidemiler, dünyadaki en önemli hasta bakımı ile ilişkili enfeksiyonlardan biridir. Candida türlerinin türe özgü antifungal duyarlıık profillerinin olması nedeni ile kandidemili hastalarda enfeksiyon etkeni türün belirlenmesi hastaların uygun tedavisi için gereklidir. Etken türün belirlenmesinde tanımlanma süresini kısaltmak için çeşitli yöntemler kullanılmaktadır. Fungal ID multipleks tandem polimeraz zincir reaksiyonu (MT-PCR) (AusDiagnostics, Avustralya), klinik örneklerden sık izole edilen maya ve küflerin tanımlanması için geliştirilmiş bir testtir. Çalışmamızda, Akdeniz Üniversitesi Hastanesi Merkez Laboratuvarında pozitif sinyal veren kan kültür şişelerinden maya morfolojisindeki mantarların tanımlanmasında Fungal ID MT-PCR testinin değerlendirilmesi amaçlanmıştır. Aralık 2016-Aralık 2017 tarihleri arasında, Gram yaymasında maya hücresi saptanan, 92 ardışık hastadan alınan kan kültürü örnekleri, Fungal ID MT-PCR ve referans yöntemle test edilmiştir. Pozitif sinyal veren kan kültür şişelerinden Sabouraud dekstroz agar besiyerine pasaj yapılmış, morfolojik tanımlama yöntemleri (germ tüp testi ve corn meal Tween ${ }^{\circledR} 80$ agar besiyerlerindeki morfolojik özellikleri vb.), BD Phoenix Yeast ID Panel (Becton Dickinson, Sparks, MD, Almanya) ve Bruker Biotyper "matrix-assisted laser desorption/ionization time-of- flight, mass spectrometry (MALDI-TOF MS)" (Bruker Daltonics, Almanya) sistemleri ile türler tanımlanmıştır. 
MALDI-TOF MS ile yapılan tanımlamalar referans yöntem olarak kabul edilmiştir. Referans yöntem ile izolatların 35'i Candida albicans, 17'si Candida glabrata, 13'ü Candida parapsilosis, 12'si Candida tropicalis, yedisi Candida krusei, ikisi Candida guilliermondii, ikisi Candida dubliniensis, ikisi Candida inconspicua, biri Candida kefyr ve biri Saprochaete capitata olarak tanımlanmıştır. Birden fazla maya türünün etken olduğu olgu bulunmamışır. Morfolojik tanımlama yöntemleri ile izolatların \%94.6'sının olası tanımı yapılmıstır. BD Phoenix Yeast ID Panel ile referans yöntem arasında uyumsuz sonuç saptanmamıştır. Fungal ID MTPCR ile izolatların 33'ü C.albicans, 15'i C.glabrata, 13'ü C.parapsilosis, 11'i C.tropicalis, beşi C.krusei, ikisi C.guilliermondii, biri C.dubliniensis, biri C.kefyrve 10'u Candida spp. olarak tanımlanmıştır. C.inconspicua ve S.capitata test panelinde yer almadığından, iki örnekte C.inconspicua Candida spp. olarak tanımlanırken, bir örnekte S.capitata tanımlanamamıştır. Fungal ID MT-PCR ve referans yöntem arasındaki uyum, tür düzeyinde $\% 88$, cins düzeyinde ise $\% 98.9$ olarak bulunmuştur. C.krusei ve C.glabrata'nın saptanmasında Fungal ID MT-PCR testinin duyarlılığı sırasıyla \%71.4 ve \%88.2 olarak saptanmıştır. Fungal ID MT-PCR testi, cins düzeyinde tanımlamada yüksek performansa sahiptir, ancak tedavi yönetimi için önemli olan tür seviyesinde tanımlamada performansı orta düzeydedir. Fungal ID MT-PCR, Candida türlerinin erken saptanması için geleneksel tanımlama yöntemlerine ek test olarak kullanılabilir.

Anahtar kelimeler: Multipleks tandem polimeraz zincir reaksiyonu; maya; kandidemi; kan kültürü; Candida'nın tanımlanması.

\section{ABSTRACT}

Candidemia is one of the most important health care-associated infections worldwide. Candida species have species-specific antifungal susceptibility profiles and it has been shown that the identification of the Candida species is necessary for the appropriate treatment of the patients with candidemia. Various methods are used to shorten the identification time for the determination of the causative species. Fungal ID multiplex tandem polymerase chain reaction (MT-PCR) (AusDiagnostics, Australia) is a test developed to identify yeasts and molds isolated from clinical specimens. In this study, we aimed to evaluate the Fungal ID MT-PCR test (AusDiagnostics, Australia) for the identification of the yeasts from positive blood cultures in Akdeniz University Hospital Central Laboratory. Between December 2016 and December 2017, blood culture samples from 92 consecutive patients with yeast cells detected in Gram stained smears were tested by Fungal ID MT-PCR and the reference method. After the subculture of the positive signaling blood culture bottles to Sabouraud dextroz agar (SDA), the identification of the yeasts were performed by morphological identification methods (Germ tube test, Corn Meal Tween ${ }^{\circledR} 80$ agar media, etc.), BD Phoenix Yeast ID Panel (Becton Dickinson, Sparks, MD) and Bruker Biotyper matrix-assisted laser desorption ionization-time of mass spectrometry (MALDI-TOF MS) (Bruker Daltonics, Germany) systems. Identification with MALDI-TOF MS have been accepted as the reference method. Thirty-five of the isolates were identified as Candida albicans, 17 were Candida glabrata, 13 were Candida parapsilosis, 12 were Candida tropicalis, seven were Candida krusei, two were Candida guilliermondii, two were Candida dubliniensis, two were Candida inconspicua, one was Candida kefyr and one was Saprochaete capitata by the reference method. In our study, no blood culture sample yielded more than one yeast species. $94.6 \%$ of the strains were presumptively identified by the morphological identification methods. Discordant results were not detected between the BD Phoenix Yeast ID Panel and the reference method. Thirty-three of the isolates were identified as C.albicans, 15 were C.glabrata, 13 were C.parapsilosis, 11 were C.tropicalis, five were C.krusei, two were C.guilliermondii, one was C.dubliniensis, one was C.kefyr and 10 were Candida spp. by Fungal ID MT-PCR assay. Since C.inconspicua and S.capitata were not included in the test panel, C.inconspicua was identified as Candida spp. in two samples, while S.capitata could not be identified in one sample. Concordance between Fungal ID MT-PCR and the reference method were found to be $88 \%$ at the species level and $98.9 \%$ at the genus level. The sensitivity of the Fungal ID MT-PCR test in in the detection of C.krusei and C.glabrata was $71.4 \%$ and $88.2 \%$, respectively. Fungal ID MT-PCR test has shown a high performance in the identification at the genus level, but the identification at the species level, which is important for the treatment management, was moderate. Fungal ID MT-PCR can be used as an adjunct test to the traditional identification methods for the early identification of the Candida species.

Keywords: Multiplex tandem polymerase chain reaction; yeast; candidemia; blood culture; Candida identification. 


\section{Giriş}

Kandidemiler, dünyadaki en önemli hasta bakımı ile ilişkili enfeksiyonlardan biridir' Candida albicans, Candida glabrata, Candida parapsilosis, Candida tropicalis, Candida krusei, Candida lusitaniae ve Candida guilliermondii kandidemilerin \%95'inden fazlasına neden olan türlerdir ${ }^{1}$. C.albicans, kandideminin en sık görülen nedeni olmasına rağmen son 10 yılda, azollere maruz kalmanın artması ile ilişkili olduğu düşünülen C.albicans dışı türlerin izolasyonundaki artış göze çarpmaktadır. Her ne kadar Candida türlerinin çoğu flukonazole duyarlı olsa da kazanılmış direnç veya doğal olarak dirençli türlerin ortaya çıkması yönünde bir eğilim bulunmaktadır ${ }^{2,3}$.

Doğru zamanda başlanan antifungal tedavi ve kaynak kontrolü, kandidemili hastalarda sağkalımın önemli belirleyicileridir. Tedavi edilmeyen kandidemilerde mortalite oranı $\% 60$ 'ın üzerinde iken, tedavi ile bu oran yaklaşık \%30-40'tır ${ }^{4-6}$. Kandidemili 230 hasta ile yapılan retrospektif bir kohort çalışmasında, maya için ilk pozitif kültürün bildirilmesinden flukonazol tedavisinin başlanmasına kadar geçen gün sayısının, artmış mortalite oranları ile korelasyon gösterdiği belirlenmiştir? ${ }^{7}$.

Candida türlerinin türe özgü antifungal duyarlılık profilleri olduğundan, enfeksiyon etkeni türün belirlenmesinin Candida kan dolaşımı enfeksiyonu olduğundan şüphelenilen hastaların uygun tedavisi için gerekli olduğu gösterilmiştir ${ }^{1}$. Kandidemilerde ekinokandinler ilk tedavi seçeneği iken, alternatif tedavi seçenekleri daha çok spesifik türle ilişkilidir$^{8}$. Bu nedenle, etken Candida türünün hızı bir şekilde tespit edilmesi, kandideminin etkili tedavisi için değerlidir.

Kandideminin tanısında altın standart pozitif kan kültürüdür. Kan kültürü, daha sonraki antifungal duyarılık testlerinin uygulanmasını sağlayan tek tanısal yaklaşımdır ${ }^{9}$. Pozitif sinyal veren kan kültür şişelerinden katı besiyerlerine pasaj sonrasında organizmanın tanımlanması için kullanılan yönteme göre bir iki gün gerekmektedir. Ciddi bir hasta için daha hızlı ve daha duyarlı teknikler gereklidir. Tanımlanma süresini kısaltmak için "peptide nucleic acid fluorescence in situ hybridization (FISH)", "matrix-assisted laser desorption ionization-time of flight mass spectrometry (MALDI-TOF-MS)" ve polimeraz zincir reaksiyonu (PCR) gibi çeşitli yöntemler kullanılmaktadır ${ }^{10-13}$. Multipleks tandem polimeraz zincir reaksiyonu (MT-PCR), tüm amplikonların aynı anda multipleks PCR ile sınırı sayıda döngü ile çoğaltıldığı ön çoğaltma (amplifikasyon) basamağı ve gerçek zamanlı PCR basamağından oluşan, çok sayıda hedefin saptanmasına izin veren iki aşamalı bir yöntemdir ${ }^{14}$.

Bu çalışmada, Akdeniz Üniversitesi Hastanesi Merkez Laboratuvarında pozitif sinyal veren kan kültür şişelerinden maya morfolojisindeki mantarların tanımlanmasında Fungal ID multipleks tandem polimeraz zincir reaksiyonunun (MT-PCR) (AusDiagnostics, Avustralya) değerlendirilmesi amaçlanmıştır.

\section{GEREÇ ve YÖNTEM}

Bu çalışma Akdeniz Üniversitesi Tıp Fakültesi Klinik Araştırmalar Etik Kurulu (2012KAEK-20) onayı ile gerçekleştirildi (Tarih: 01.06.2016 ve Karar no: 2016/313). 


\section{Kan Kültürleri}

Aralık 2016-Aralık 2017 tarihleri arasında, Akdeniz Üniversitesi Hastanesinde yatan hastalardan alınan kan kültürleri, Akdeniz Üniversitesi Hastanesi Merkez Laboratuvarında, BD BACTEC FX (Becton Dickinson, ABD) kan kültür sisteminde sinyal verinceye kadar veya beş gün süresince inkübe edildi. Pozitif sinyal veren kan kültürlerinden hazırlanan yayma preparatları Gram boyama yöntemi ile boyandı ve yaymada maya hücreleri saptanan ardışık 92 farklı hastadan alınan kan kültürü örneği çalışmaya dahil edildi. Pozitif sinyal veren kan kültür şişelerinden Sabouraud dekstroz agar (SDA) besiyerine pasaj yapıldı.

\section{Morfolojik Tanımlama Yöntemleri}

İolatlar; germ tüp testi, CHROMagar ${ }^{\mathrm{TM}}$ Candida (Becton Dickinson, ABD) besiyerindeki koloni renkleri, corn meal Tween ${ }^{\circledR} 80$ agar besiyerlerindeki morfolojik özellikleri kullanılarak tanımlandı.

\section{Otomatize Yöntem ve MALDI-TOF MS}

BD Phoenix Yeast ID Panel (Becton Dickinson, Sparks, MD, Almanya) ve Bruker Biotyper MALDI-TOF MS (Bruker Daltonics, Almanya), üretici firmaların önerileri doğrultusunda çalışıldı. MALDI-TOF MS ile yapılan tanımlamalar referans yöntem olarak kabul edildi ${ }^{15-17}$.

\section{Multipleks Tandem PCR Yöntemi ile Türlerin Tanımlanması}

Fungal ID MT-PCR testi; Candida spp., Candida albicans, Candida dubliniensis, Candida glabrata, Candida parapsilosis, Candida guilliermondii, Candida krusei, Candida tropicalis, Candida famata, Candida kefyr, Fusarium spp., Fusarium solanii, Scedosporium prolificans, Cryptococcus neoformans, Saccharomyces cerevisiae, Yarrowia lipolytica ve Aspergillus türlerinin kan kültürü, besiyerinde üreyen koloniler, tam kan, serum ve plazmadan saptanması için tasarlanmış bir testtir. Fungal ID MT-PCR testi ile kan kültüründe etken tür yaklaşık üç saat içinde belirlenebilmektedir.

Ticari bir kit ile (EZ1 Virus Mini Kit, Qiagen, Birleşik Krallık) DNA izolasyonunun ardından, Fungal ID MT-PCR kiti ile izolatlar tanımlandı. Multipleks Tandem PCR (MT-PCR), iki aşamalı bir PCR yöntemidir. Bu yöntemde ilk aşamada, tüm amplikonlar aynı anda multipleks PCR ile 15 veya 18 döngü boyunca çoğaltıldı. Bu döngü sayısı boyunca çok az dNTP tüketildiği için her PCR reaksiyonu diğerlerinden bağımsız olup her hedefin nispi miktarı korunmaktadır. İlk aşamada elde edilen ürün, dilüsyon sonrasında her bir hedef için bir adet olacak şekilde PCR reaksiyon sayısı kadar paylaştırılmıştır. İkinci aşamada kullanılan primer dizileri, ilk aşamada kullanılan primer dizilerinin iç bölgelerinden seçildiği için ilk aşamada sentezlenen özgül olmayan amplikonlar, ikinci aşamada çoğaltılamamaktadır.

\section{İstatistiksel Analiz}

Referans yöntem olan MALDI-TOF MS tanımlaması ile her bir yöntemin (morfolojik tanımlama, BD Phoenix Yeast ID Panel ve Fungal ID MT-PCR) tanımlaması ayrı ayrı kar- 
şılaştırıldı. Referans yöntemin pozitifliği gerçek pozitif olarak alınarak diğer yöntemlerin duyarlılığı hesaplandı.

\section{BULGULAR}

Çalışma kapsamında kandidemili 92 hastanın 28'i yoğun bakım, 28'i dahili bilim, 12'si cerrahi bilim, 16'sı çocuk hastalıkları ve sekizi çocuk yoğun bakım kliniklerinde takip edilmiştir.

Referans yöntem olan MALDI-TOF MS ile izolatların 35'i C.albicans, 17'si C.glabrata, 13'ü C.parapsilosis, 12'si C.tropicalis, yedisi C.krusei ikisi C.guilliermondii, ikisi C.dubliniensis, ikisi C.inconspicua, biri C.kefyr ve biri Saprochaete capitata olarak tanımlanmıştır. Birden fazla maya türünün etken olduğu herhangi bir olgu saptanmamıştır.

Morfolojik tanımlama yöntemleri ile 92 izolatın 87 (\%94.6)'sinin olası tanımı yapılabilmiştir. BD Phoenix Yeast ID Panel ile 92 izolatın tümü tür düzeyinde tanımlanmış ve referans yöntem ile uyumsuz sonuç saptanmamıştır. Morfolojik tanımlama yöntemleri ve BD Phoenix Yeast ID Panel'in referans yöntem ile karşılaştırma sonuçları Tablo I'de gösterilmiştir.

Fungal ID MT-PCR ile izolatların 33'ü C.albicans, 15'i C.glabrata, 13'ü C.parapsilosis, $11^{\prime}$ i C.tropicalis, beşi C.krusei, ikisi C.guilliermondii, biri C.dubliniensis, biri C.kefyr ve 10'u Candida spp. olarak tanımlanmıştır. Fungal ID MT-PCR, 92 pozitif sinyal veren kan kültürü şişesinin 81 'inde mayaları tür düzeyinde tanımlayabilmiştir. Bu testte C.inconspicua ve S.capitata için hedef bulunmadığından, iki örnekte C.inconspicua Candida spp. olarak tanımlanırken, bir örnekte S.capitata tanımlanamamıştır. Test panelinde bulunmayan C.inconspicua ve S.capitata hariç tutulduğunda, Fungal ID MT-PCR testinin tür düzeyinde tanımlamada duyarlııı oranının \%50-100 arasında değiştiği saptanmıştır (Tablo I). Fungal ID MT-PCR testinin flukonazole doğal dirençli C.krusei'yi saptama duyarlılığı \%71.4 iken, azollere dirençli olabilen C.glabrata'yı saptama duyarlılığı \%88.2 olarak belirlenmiştir. Fungal ID MT-PCR ve referans yöntem arasındaki uyum, tür düzeyinde \%88, cins düzeyinde ise \%98.9 olarak bulunmuştur. Fungal ID MT-PCR testinin, referans yöntem ile karşılaştırıldığında her tür için saptanan duyarlılık oranı ve iki yöntem arasındaki uyum Tablo I'de gösterilmiştir. Referans yöntem ile karşılaştırıldığında Fungal ID MT-PCR ile tür düzeyinde uyumsuz sonuç elde edilen izolatlar Tablo II'de gösterilmiştir.

\section{TARTIŞMA}

Kandidemi ile ilişkili yüksek mortaliteyi azaltmak, uygun antifungal tedaviye mümkün olduğunca erken başlamak için etkenin tür düzeyinde tanımlanması önemlidir. Antifungal tedavi Candida türüne göre değişebilmektedir, ayrıca kan kültüründe üreyen mayalar her zaman Candida değildir, fungemili hastaların yaklaşık \%5'inde etken, Candida dışı maya türleridir ${ }^{18,19}$.

Çalışmamızda, en sık izole edilen tür olan C.albicans'ı, C.glabrata, C.parapsilosis, C.tropicalis ve C.krusei izlemiştir. Kandidemi insidansında olduğu gibi, genel tür dağılımı coğrafi bölgeye ve hasta popülasyonuna bağlı olarak değişmektedir. Hastanemizde 


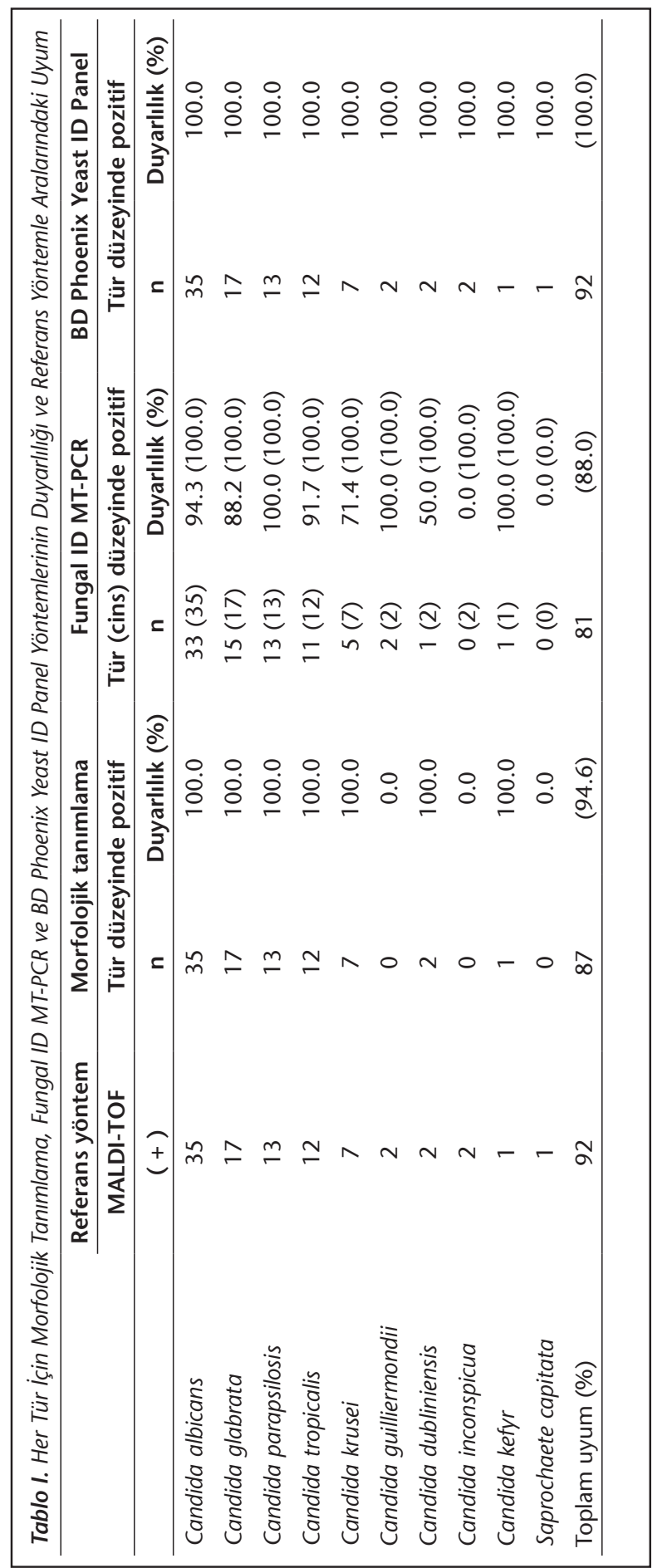




\begin{tabular}{|lc|}
\hline \multicolumn{2}{|l}{$\begin{array}{l}\text { Tablo II. Referans Yöntem ile Karşılaştıııldığında Fungal ID MT-PCR ile Tür Düzeyinde Uyumsuz Sonuç Elde } \\
\text { Edilen İzolatlar }\end{array}$} \\
\hline & Uyumsuz tanımlama sonucu $(\mathrm{n})$ \\
\cline { 2 - 2 } Referans yöntem (MALDI-TOF MS) ile tanımlanan izolatlar & Fungal ID MT-PCR \\
\hline Candida albicans $(\mathrm{n}=35)$ & Candida spp. $(\mathrm{n}=2)$ \\
Candida glabrata $(\mathrm{n}=17)$ & Candida spp. $(\mathrm{n}=2)$ \\
Candida tropicalis $(\mathrm{n}=12)$ & Candida spp. $(\mathrm{n}=1)$ \\
Candida krusei $(\mathrm{n}=7)$ & Candida spp. $(\mathrm{n}=2)$ \\
Saprochaete capitata $(\mathrm{n}=1)$ & Tanımlanamadı $(\mathrm{n}=1)$ \\
\hline
\end{tabular}

genellikle en sık görülen C.albicans dışı kandidemi etkeni C.parapsilosis'tir ${ }^{20}$. Bu çalışmada farklı olarak en sık C.albicans dışı kandidemi etkeninin C.glabrata olduğu belirlenmiştir. Önceden kullanılan antifungal tedavi, profilaktik flukonazol kullanımına bağlı seçici baskı, immünsupresyon, geniş spektrumlu antibiyotik kullanımı, ileri yaş gibi faktörler C.glabrata ile enfeksiyonların sıklığının artışına katkıda bulunmaktadır ${ }^{19}$.

Candida türleri, nozokomiyal kan dolaşımı enfeksiyonlarıyla ilişkili en yaygın patojenlerden birini temsil etmektedir. Kandidemi ayrıca yüksek mortalite, hastanede uzun kalış süresi ve artan sağlık maliyetleri ile ilişkilidir. Bu olumsuz sonuçlar, kandidemi için basitleştirilmiş aerodinamik tanı yöntemlerinin bulunmaması nedeni ile günümüz klinik pratiğinde geçerli olmaya devam etmektedir ${ }^{21}$. Kültüre dayalı olmayan yöntemler, bağışıklığı baskılanmış hastalarda kandideminin erken tanısını desteklemek için hız avantajına sahiptir. Moleküler tanı yöntemleri kullanılarak kan kültürlerinden mayaların hızlı bir şekilde tanımlanmasının, özellikle antimikrobiyal yönetişim ile birleştirildiğinde, antifungal tedavinin erken uygulanmasıyla klinik sonuçların iyileşmesine katkıda bulunacağı bildirilmiştir ${ }^{22}$.

Morfolojik tanımlama yöntemlerinin tüm biyokimyasal tanımlama sistemlerine eşlik etmesi önerilmektedir ${ }^{23}$. Çalışmamızda, morfolojik tanımlama yöntemleri ile maya izolatlarının \%94.6'sının olası tanımı yapılabilmiştir. Bu yöntemler deneyim gerektirir, ancak bu deneyimi kazandıktan sonra izolatların büyük bölümünün tanımlanmasında kullanılabilmektedir.

BD Phoenix Yeast ID Panel'in diğer sistemlerle karşılaştırıldığı çalışmalarda; BD Phoenix Yeast ID Panel ile API ${ }^{\circledR}$ ID 32C (bioMérieux, Fransa), Remel RapID Yeast Plus System, API 20C AUX sistemi ve MALDI-TOF MS ile uyum, sırasıyla \%75.4, \%93.3, \%91.5 ve \%9599.2 olarak saptanmıştır ${ }^{24-28}$. Yapılan çeşitli çalışmalarda, BD Phoenix Yeast ID Panel'in mayaları doğru tanımlama oranı \%89'un üzerinde bulunmuştur ${ }^{25,29,30}$. BD Phoenix Yeast ID Panel'in mayaları doğru tanımlama oranı maya türlerine göre değişmekte olup, sistem, yaygın maya türlerinin \%98-98.2'sini doğru tanımlarken, bu oran nadir türler için \%7076'ya düşmektedir ${ }^{25}$. Çalışmamızda referans yöntem ile BD Phoenix sistemi arasındaki yüksek uyumun, çalışmada yer alan türlerin dağılımı ile ilgili olabileceğini düşünmekteyiz. 
Bu çalışmada, Fungal ID MT-PCR ile 92 örneğin 81 (\%88)'inde etken tür düzeyinde, 91 (\%98.9)'inde ise cins düzeyinde doğru olarak tanımlanmıştır. Kan kültüründe maya saptanan olgularda ilk tedavi seçeneği ekinokandinler olup, flukonazol, durumu kritik olmayan hastalarda ve C.glabrata veya C.krusei gibi flukonazole dirençli bir organizma ile enfekte olma olasılığı düşük olan hastalarda alternatif ajan olarak kullanılabilmektedir. Fungal ID MT-PCR'nin türleri belirlemedeki duyarlılığı türden türe değişmektedir. Testin C.krusei ve C.glabrata'yı saptamada duyarlılığının sırasıyla \%71.4 ve \%88.2 olması nedeni ile test ile sonuç alınamayan veya Candida spp. olarak tanımlanan olgularda rutin tanımlama ve antifungal duyarlılık test sonuçlarına göre tedavinin düzenlenmesi gereklidir ${ }^{8,10}$.

Lau A ve arkadaşlarının çalışmasında ${ }^{31}$, kan kültüründe maya saptanan 44 olgunun 42'sinde fungal ID MT-PCR ve konvansiyonel yöntem sonuçları uyumlu bulunmuştur. Fungal ID MT-PCR ile negatif sonuç alınan iki örneğin birinden Candida nivariensis, diğerinden ise Kodamaea ohmeri ve Candida lambica izole edilmiştir. Fungal ID MT-PCR testinde bu mayalar test panelinde yer almadığı için negatif sonuç alınmıştır. Benzer şekilde, çalışmamızdaki test panelinde de yer almadığı için bir örnekte S.capitata tanımlanamamış, iki örnekte ise C.inconspicua cins düzeyinde tanımlanmıştır.

Kültür plaklarında üremiş 183 klinik izolatın koloni MT-PCR ve fenotipik yöntemlerle tanımlandığı bir çalışmada, 183 izolatın tümünün koloni MT-PCR testi ile doğru bir şekilde tanımlandığı belirlenmiş̧tir ${ }^{32}$. Ayrıca fungal ID MT-PCR kan, serum ve plazma örneklerinde de çalışılabilmektedir. Kan örneği kullanıldığında, kandidemili hastaların \%70'inde enfeksiyonu dört gün kadar erken tespit edebildiği bildirilmiştir ${ }^{33}$.

Bu çalışmanın kısıtlılıklarından biri, testin değerlendirilmesi için az sayıda örnek kullanılması, diğer bir kısıtılığı ise izolatların tanımlanmasında dizi analizi yapılamamış olmasıdır. Sonuçlarımız mayaların tanımlanması için geçerli olsa da fungal ID MT-PCR, Aspergillus spp., Fusarium spp. ve S.prolificans gibi küflerin neden olduğu kan dolaşımı enfeksiyonlarının tanısında da kullanılabilmektedir.

Referans yöntem olarak kullandığımız MALDI-TOF MS, Candida, Cryptococcus, Rhodotorula ve Saccharomyces türleri de dahil olmak üzere birçok mayanın tanımlanmasında oldukça etkili olduğu kanıtlanmış, geniş veri tabanına sahip bir sistemdir ${ }^{16}$. Fungal ID MTPCR testi ise sınırlı bir dizi Candida türünü saptamak üzere tasarlanmıştır. Lokal epidemiyolojik veriler göz önüne alındığında, nadir saptanan maya türleri ile enfeksiyon sıklığının yüksek olduğu hastanelerde fungal ID MT-PCR testinin tek başına kullanılmasının uygun olmadığını düşünmekteyiz.

Fungal ID MT-PCR testinin cins düzeyinde tanımlamada performansının yüksek olduğu, ancak tedavi yönetimi için önemli olan tür düzeyinde tanımlama başarısının orta düzeyde olduğu belirlenmiştir.

Bu değerlendirmeye göre, testin seçilmiş hastalarda geleneksel tanımlama yöntemlerini tamamlayıcı test olarak kullanılabileceğini düşünmekteyiz. Klinik laboratuvarlar, kültüre dayalı olmayan yöntemler arasında seçim yaparken farklı seçeneklerle karşılaşabilmekte- 
dir. Bu yöntemlerin hasta bakımında kullanılmak üzere uygulanmasından önce daha fazla validasyon ve standardizasyon çalışması yapılmalıdır. Sonuç olarak, tanısı zor olan invaziv kandidemi için hızlı tanı yöntemlerinde daha fazla iyileştirmeye ihtiyaç bulunmaktadır.

\section{ETIK KURUL ONAYI}

Bu çalışma, Akdeniz Üniversitesi Tıp Fakültesi Klinik Araştırmalar Etik Kurulu (2012KAEK-20) onayı ile gerçekleştirildi (Tarih: 01.06.2016 ve Karar no: 2016/313).

\section{ÇIKAR ÇATIŞMASI}

Yazarlar bu makale ile ilgili herhangi bir çıkar çatışması bildirmemişlerdir.

\section{KAYNAKLAR}

1. Ao W, Klonoski J, Berlinghoff E, Jensen J, Afroz T, Munns D, et al. Rapid detection and differentiation of clinically relevant Candida species simultaneously from blood culture by use of a novel signal amplification approach. J Clin Microbiol 2017; 56(1): e00982-17.

2. Pfaller MA, Diekema DJ. Epidemiology of invasive mycoses in North America. Crit Rev Microbiol 2010; 36(1): $1-53$.

3. Lamoth F, Lockhart SR, Berkow EL, Calandra T. Changes in the epidemiological landscape of invasive candidiasis. J Antimicrob Chemother 2018; 73(S1): i4-i13.

4. Fraser VJ, Jones M, Dunkel J, Storfer S, Medoff G, Dunagan WC. Candidemia in a tertiary care hospital: epidemiology, risk factors, and predictors of mortality. Clin Infect Dis 1992; 15(3): 414-21.

5. Andes DR, Safdar N, Baddley JW, Playford G, Reboli AC, Rex JH, et al. Impact of treatment strategy on outcomes in patients with candidemia and other forms of invasive candidiasis: a patient-level quantitative review of randomized trials. Clin Infect Dis 2012; 54(8): 1110-22.

6. Clancy CJ, Nguyen $\mathrm{MH}$. The end of an era in defining the optimal treatment of invasive candidiasis. Clin Infect Dis 2012; 54(8): 1123-5.

7. Garey KW, Rege M, Pai MP, Mingo DE, Suda KJ, Turpin RS, et al. Time to initiation of fluconazole therapy impacts mortality in patients with candidemia: a multi-institutional study. Clin Infect Dis 2006; 43(1): 25-31.

8. Pappas PG, Kauffman CA, Andes DR, Clancy CJ, Marr KA, Ostrosky-Zeichner L, et al. Clinical practice guideline for the management of candidiasis: 2016 update by the Infectious Diseases Society of America. Clin Infect Dis 2016; 62(4): e1-50.

9. Kullberg BJ, Arendrup MC. Invasive Candidiasis. N Engl J Med 2016; 374(8): 794-5.

10. Doğan Ö, İnkaya AÇ, Gülmez D, Uzun Ö, Akova M, Arıkan Akdağlı S. Evaluation of PNA-FISH method for direct identification of Candida species in blood culture samples and its potential impact on guidance of antifungal therapy. Mikrobiyol Bul 2016; 50(4): 580-9.

11. Aydemir G, Koç AN, Atalay MA. Evaluation of peptide nucleic acid fluorescent in situ hybridization (PNA FISH) method in the identification of Candida species isolated from blood cultures. Mikrobiyol Bul 2016; 50(2): 293-9.

12. Turhan O, Ozhak-Baysan B, Zaragoza O, Er H, Saritas ZE, Ongut G, et al. Evaluation of MALDI-TOF-MS for the identification of yeast isolates causing bloodstream infection. Clin Lab 2017; 63(4): 699-703.

13. Ağca H, Dalyan Cilo B, Özmerdiven GE, Sağlam S, Ener B. Development of a real-time polymerase chain reaction method for the identification of Candida species. Mikrobiyol Bul 2015; 49(1): 56-65.

14. Lewis White P, Perry MD, Barnes RA. Candida, pp: 551-68. In: Liu D (ed), Molecular Detection of Human Fungal Pathogens. 2011, 1st ed. Boca Raton, Florida.

15. Ling H, Yuan Z, Shen J, Wang Z, Xu Y. Accuracy of matrix-assisted laser desorption ionization-time of flight mass spectrometry for identification of clinical pathogenic fungi: a meta-analysis. J Clin Microbiol 2014; 52(7): 2573-82. 
16. Terrero-Salcedo D, Powers-Fletcher MV. Updates in laboratory diagnostics for invasive fungal infections. J Clin Microbiol 2020; 58(6): e01487-19.

17. Patel R. A Moldy Application of MALDI: MALDI-ToF mass spectrometry for fungal identification. J Fungi (Basel) 2019; 5(1): 4.

18. Cuenca-Estrella M, Verweij PE, Arendrup MC, Arikan-Akdagli S, Bille J, Donnelly JP, et al. ESCMID* guideline for the diagnosis and management of Candida diseases 2012: diagnostic procedures. Clin Microbiol Infect 2012; 18(S7): 9-18.

19. Horn DL, Neofytos D, Anaissie EJ, Fishman JA, Steinbach WJ, Olyaei AJ, et al. Epidemiology and outcomes of candidemia in 2019 patients: data from the prospective antifungal therapy alliance registry. Clin Infect Dis 2009; 48(12): 1695-703.

20. Cicek-Kolak C, Erman-Daloglu A, Ozhak B, Ogunc D, Gunseren F. Epidemiology of candidemia, antifungal susceptibilities of Candida species and their impact on mortality in adult patients admitted to Akdeniz University Hospital. Klimik Journal 2019; 32(3): 250-8.

21. Bomkamp JP, Sulaiman R, Hartwell JL, Desai A, Winn VC, Wrin J, et al. Evaluation of a rapid fungal detection panel for identification of candidemia at an academic medical center. J Clin Microbiol 2020; 58(3): e0140819.

22. Simor AE, Porter V, Mubareka S, Chouinard M, Katz K, Vermeiren C, et al. Rapid identification of Candida species from positive blood cultures by use of the filmarray blood culture identification panel. J Clin Microbiol 2018; 56(12): e01387-18.

23. Walsh T, Hayden R, Larone D. Laboratory Technique, pp: 359-426. In: Larone's Medically Important Fungi: A Guide to Identification. 2018, 6th ed. ASM Press, Washington DC.

24. Gayibova Ü, Dalyan Cılo B, Ağca H, Ener B. Klinik örneklerden izole edilen Candida türlerinin tanımlanmasında Phoenix ${ }^{\mathrm{TM}}$ Yeast ID Panel ile API(囚) ID 32C ticari sistemlerinin karşılaştırılması. Mikrobiyol Bul 2014; 48(3): 438-48.

25. Grant ML, Parajuli S, Deleon-Gonsalves R, Potula R, Truant AL. Comparative evaluation of the BD Phoenix Yeast ID Panel and Remel RapID Yeast Plus system for yeast identification. Can J Infect Dis Med Microbiol 2016; 2016: 4094932.

26. Kanesaka I, Kanayama A, Itou T, Uchino U, Koyama H, Matsuzaki K, et al. Evaluation of the BD Phoenix ID Yeast System for the species identification of clinical yeast-like organisms. Kansenshogaku Zasshi 2017; 90(6): 787-91.

27. Marucco AP, Minervini P, Snitman GV, Sorge A, Guelfand LI, Moral LL, et al. Comparison of the identification results of Candida species obtained by BD Phoenix ${ }^{\mathrm{TM}}$ and Maldi-TOF (Bruker Microflex LT Biotyper 3.1). Rev Argent Microbiol 2018; 50(4): 337-40.

28. Er H, Koyuncu-Ozyurt O, Ozhak B, Yazisiz H, Eres Saritas Z, Cetinkaya O, et al. Evaluation of an automated yeasts identification system for identification of yeast isolates. Clin Lab 2020; 66(1).

29. Chao QT, Lee TF, Teng SH, Peng LY, Chen PH, Teng LJ, et al. Comparison of the accuracy of two conventional phenotypic methods and two MALDI-TOF MS systems with that of DNA sequencing analysis for correctly identifying clinically encountered yeasts. PLoS One 2014; 9(10): e109376.

30. Posteraro B, Ruggeri A, De Carolis E, Torelli R, Vella A, De Maio F, et al. Comparative evaluation of BD Phoenix and vitek 2 systems for species identification of common and uncommon pathogenic yeasts. J Clin Microbiol 2013; 51(11): 3841-45.

31. Lau A, Sorrell TC, Chen S, Stanley K, Iredell J, Halliday C. Multiplex tandem PCR: a novel platform for rapid detection and identification of fungal pathogens from blood culture specimens. J Clin Microbiol 2008; 46(9): 3021-7.

32. Lau A, Sorrell TC, Lee O, Stanley K, Halliday C. Colony multiplex-tandem PCR for rapid, accurate identification of fungal cultures. J Clin Microbiol 2008; 46(12): 4058-60.

33. Lau A, Halliday C, Chen SC, Playford EG, Stanley K, Sorrell TC. Comparison of whole blood, serum, and plasma for early detection of candidemia by multiplex-tandem PCR. J Clin Microbiol 2010; 48(3): 811-6. 